\title{
水相可见光催化反应研究进展
}

\author{
陈丹刘剑沉张馨元蒋合众李加洪* \\ (西南交通大学生命科学与工程学院 成都 610031)
}

\begin{abstract}
摘要 水作为生命体内化学反应的介质, 安全、廉价、易得, 具有绿色反应介质的一切特性; 而可见光是一种清洁、可 再生的自然资源，探索水相中光照条件下的可控自由基反应，发展绿色、高效的合成方法，不仅符合当今绿色化学主 题, 而且在理论和实际应用上具有重要的科学意义. 对近年来水相可见光催化反应进行了综述, 并对相应的机理进行 了讨论.

关键词 水相; 可见光; 自由基; 绿色化学
\end{abstract}

\section{Recent Advances in Aqueous Phase Visible Light Catalytic Reactions}

\author{
Chen, Dan Liu, Jianchen Zhang, Xinyuan Jiang, Hezhong Li, Jiahong* \\ (School of Life Science and Engineering, Southwest Jiaotong University, Chengdu 610031)
}

\begin{abstract}
Water is a medium for reaction in living organisms, which is safe, cheap and easy to obtain, and visible light is a clean and renewable natural resource. Exploring the controllable free radical reaction under the illumination condition in water and developing a simple, green and efficient synthesis method not only conform to the current green chemistry theme, but also have an important scientific significance in theory and practical application. The classification and review of visible light catalysis in aqueous phase have been carried out in recent years, and the corresponding mechanisms are discussed.
\end{abstract}

Keywords water; visible light; radical; green chemistry

20 世纪下半叶以来, 随着全球经济的快速腾飞, 人 类物质生活方面得到极大发展, 同时生态环境破坏问题 却日趋严重. 大量化学产物的肆意排放, 已经严重威胁 到了人类的生存. 因此, 减少化学过程中的有毒或污染 废物的绿色化学得到了广泛的青睐 ${ }^{[1]}$. 一般来说, 反应 系统中的化学污染主要来源于有机溶剂和金属催化剂 的大规模使用. 因此, 环境友好型溶剂与新型催化剂的 研究已成为化学研究中最具吸引力的领域之一 ${ }^{[2]}$.

水是地球生命的基础 ${ }^{[3]}$, 是生物体内酶催化反应的 优良介质, 廉价、易得, 同时具有无毒、不致癌、不致 突变和不易燃烧爆炸等绿色反应介质的所有特性 ${ }^{[4]}$. 用 水来代替有机溶剂, 符合当今绿色化学的主题 ${ }^{[5]}$. 近年 来, 以水为溶剂的金属催化 ${ }^{[6]} 、$ 生物催化 ${ }^{[7]}$ 和胶束催化 ${ }^{[8]}$ 等在加快反应速率中具有广阔的应用前景, 在水相中实 现有机合成反应已经取得了重大进展 ${ }^{[9]}$.
光催化反应是在光和催化剂的同时作用下所进行 的化学反应, 是光反应和催化反应的融合. 1972 年, Fujishima 和 $\mathrm{Honda}^{[10]}$ 在 $\mathrm{n}$ 型半导体 $\mathrm{TiO}_{2}$ 单晶电极上实现 了水的光电催化分解, 自此光催化正式进入了人类的视 野. 光催化, 特别是可见光催化, 是当前有机化学的前 沿研究领域, 近年来可见光介导的有机化学反应研究获 得了突飞猛进的发展 ${ }^{[11]}$. 可见光是一种清洁的、可再生 的自然资源 ${ }^{[12]}$. 与传统的金属催化、有机小分子催化以 及酶催化相比较, 光催化剂具有用量少、反应条件温和、 底物适用性好以及实验操作简单等优点 ${ }^{[13]}$.

目前为止, 绝大多数光催化反应都是在有机相中进 行 $^{[14]}$, 在纯水相中进行可见光介导的有机反应报道鲜 少. 在已有的水参与的光催化反应中, 水往往和有机溶 剂一起作为双相溶剂 ${ }^{[15]}$; 有时水还作为底物参与反应; 在其它反应中水虽然没有参与反应, 但是水对反应有显

\footnotetext{
* Corresponding author. E-mail: jiahongljh@163.com

Received July 8, 2019; revised August 1, 2019; published online August 7, 2019

Project supported by the National Natural Science Foundation of China (No. 21901216), the Fundamental Research Funds for the Central Universities (No. 2682017CX091) and the 13th Personalized Experimental Project and the Student Research Training Program (Nos. GX201913085, GX201913108).

国家自然科学基金(No. 21901216)、中央高校基本科研业务经费(No. 2682017CX091)和 2019 年第十三期个性化实验(Nos. GX201913085, GX201913108) 资助项目.
} 
著的促进作用 ${ }^{[16]}$. 对近年来水参与以及水作为反应介 质的可见光催化的有机化学反应进行综述, 并对相应的 机理进行讨论.

\section{1 水促进的可见光催化反应}

水具有的许多独特的物理和化学性质, 如极性和双 亲性等, 均来源于水的独特结构一一大量的氢键 ${ }^{[17]}$, 研 究发现水有时还能够提高反应速率以及影响各种有机 反应的选择性 ${ }^{[6 b, 18]}$.

2015 年, 陈庆云等 ${ }^{[14]}$ 在水存在下, 氧气中, 可见光 诱导苯乙烯与 1,1,1-三氟-2-碘乙烷发生光氧化还原双官 能化反应，得到 $\gamma$-三氟甲基醇(Eq. 1). 在该自由基反应 中, 产物中的氧原子来自分子氧, 其中水显示出对反应 有促进作用。反应底物可适用于在芳环上带有给电子和 卤素取代基的苯乙烯以及在双键的 $\beta$-位具有取代基的 苯乙烯。

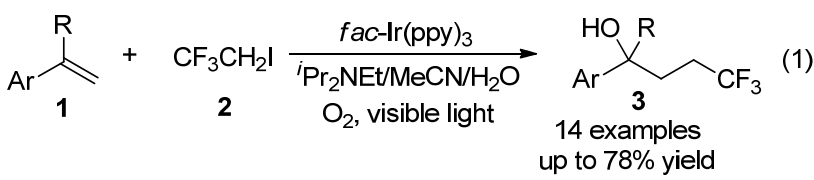

作者提出了该反应的反应机理见 Scheme 1. 首先, 可见光照射 $f a c-\operatorname{Ir}(\mathrm{III})(\mathrm{ppy})_{3}$, 经金属-配体电荷转移 (MLCT)产生氧化还原活性光激发态 $f a c-\operatorname{Ir}(\mathrm{IV})(\mathrm{ppy})_{2}-$ $\left(\mathrm{ppy}^{\cdot-}\right),{ }^{i} \mathrm{Pr}_{2} \mathrm{NEt}$ 作为还原猝灭剂, $f a c-\operatorname{Ir}(\mathrm{IV})-(\mathrm{ppy})_{2}\left(\mathrm{ppy}^{\cdot-}\right.$ ) 接受来自 ${ }^{i} \mathrm{Pr}_{2} \mathrm{NEt}$ 的电子, 产生的 $f a c-\operatorname{Ir}(\mathrm{III})(\mathrm{ppy})_{2}\left(\mathrm{ppyy}^{{ }^{--}}\right.$) 具有很高的还原能力, 通过 $f a c-\operatorname{Ir}(\mathrm{III})(\mathrm{ppy})_{2}\left(\mathrm{ppy}^{*-}\right)$ 单电 子还原 $\mathrm{CF}_{3} \mathrm{CH}_{2} \mathrm{I}$ 产生自由基阴离子, 然后产生 2,2,2-三 氟乙基 $\left(\mathrm{CF}_{3} \mathrm{CH}_{2} \bullet\right)$, 如果反应在 $\mathrm{O}_{2}$ 中进行, 则三氟乙基 可以通过捕获分子氧生成 $\mathrm{CF}_{3} \mathrm{CH}_{2} \mathrm{OH}$. 在另一种途径

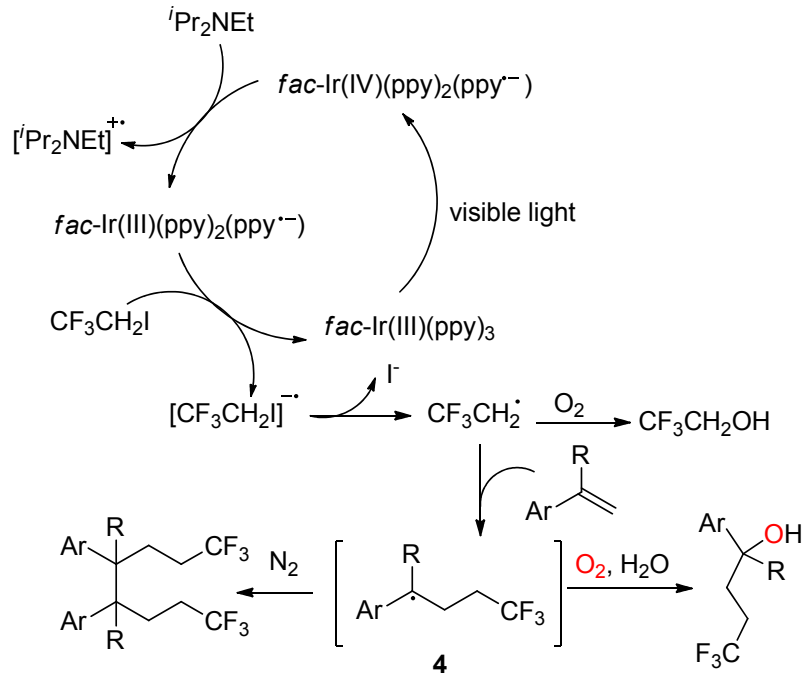

图式 1 苯乙烯的 2,2,2-三氟乙基化反应机理

Scheme 1 Mechanism of 2,2,2-trifluoroethylation of styrene

中，三氟乙基可与苯乙烯反应得到芐基自由基 4 , 在分 子氧存在下被水促进, 得到羟基产物; 如果反应在 $\mathrm{N}_{2}$ 中 进行，则苄基自由基 $\mathbf{4}$ 与其自身偶联，得到二聚产物.

2014 年, Rueping 等 ${ }^{[16]}$ 在可见光光氧还原催化下, 建立了 $N$-取代的差胺与烯烃的新的氧化 $[3+2]$ 环加成反 应(Scheme 2). 这种新颖的策略对五元环异啞唑烷杂环 化合物提供了简洁、快速、温和和高效的合成方法，水 的参与加速了反应速率. 研究其机理发现, 在光氧还原 循环后，水对反应速率起着决定性的作用.

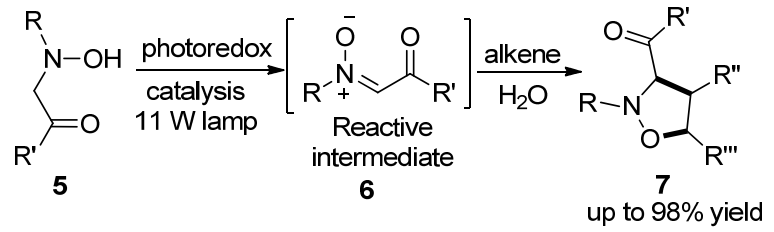

图式 $2 N$-取代的差胺与烯烃的 $[3+2]$ 环加成反应 Scheme $2[3+2]$ cycloaddition reaction of $N$-substituted hydroxylamine with olefins

\section{2 水作为反应物参与可见光反应}

水不仅可以作为一种廉价、无毒、不易燃、高度稳 定且易处理的 “绿色” 溶剂，有时还可以参与反应过程.

2014 年，肖文精和陈加荣等 ${ }^{[19]}$ 在光氧化还原催化 剂 $f a c-\operatorname{Ir}(\mathrm{ppy})_{3}$ 的存在和可见光照射下，由 3-溴甲氧基吲 哚、 $N, N$-二甲基甲酰胺(DMF)和水得到了 3-甲酰氧基吲 哚. 这是一种新颖且有效的可见光诱导的自由基加成/ 氧化/水解级联反应(Eq. 2), 该转化可直接在差吲哚的 $\mathrm{C}-3$ 位连接甲酰氧基. 其中 DMF 作为“ $\mathrm{H}, \mathrm{C}, \mathrm{O}$ ”源, $\mathrm{H}_{2} \mathrm{O}$ 作为 “ $\mathrm{O}$ ” 源. 该反应适用范围广泛，其中带有吸电子、 中性电子和给电子取代基的化合物都以良好的产率得 到相应的产物.
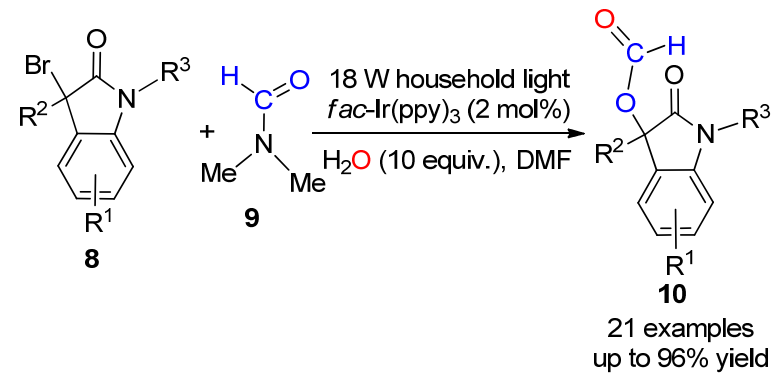

该反应的机理见 Scheme 3, 首先光催化剂 $f a c-$ $\operatorname{Ir}(\mathrm{ppy})_{3}$ 通过可见光照射激发到高活性态 $f a c-\operatorname{Ir} *(\mathrm{ppy})_{3}$, 然后与烷基溴 $8 \mathrm{a}$ 反应, 形成自由基中间体 11, 通过氧 化猝灭循环释放溴离子和 $\mathrm{fac}-\operatorname{Ir}(\mathrm{ppy})_{3}{ }^{+}$, 随后，中间体 11 和 DMF 发生自由基加成反应，得到自由基中间体 12. 12 被氧化成亚胺离子 13 , 可能通过两种途径: (1)中间体 12 被 $f a c-\operatorname{Ir}(\mathrm{ppy})_{3}^{+}$氧化, 再生基态 $f a c-\operatorname{Ir}(\mathrm{ppy})_{3}$ 完成催化循 环(路径 A); (2)中间体 12 被另一个分子 $8 \mathrm{a}$ 氧化, 通过链 


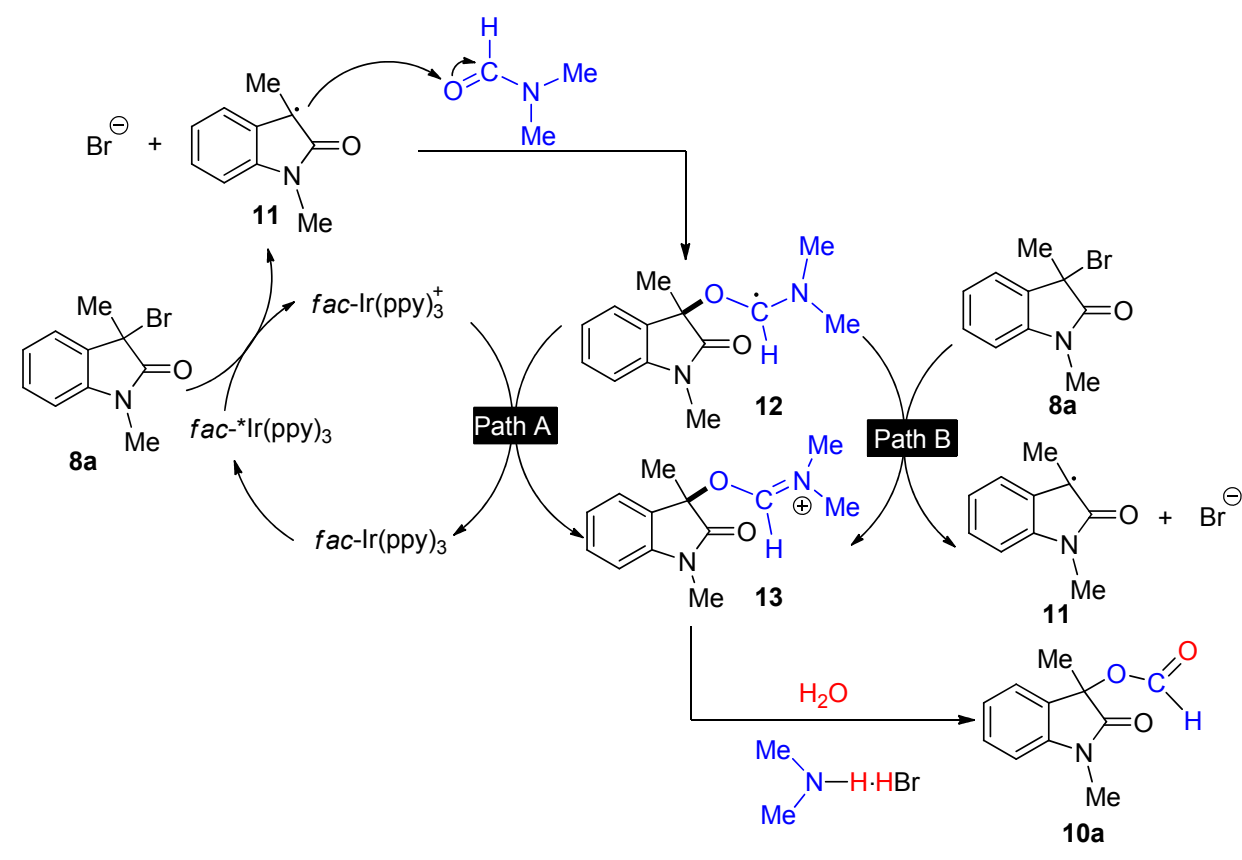

图式 3 可见光诱导的 3-溴甲基吲哚光催化甲酰氧基化反应的机理

Scheme 3 Mechanism of photocatalytic oxidation of 3-bromomethylhydrazine photocatalytic reaction induced by visible light

增长机制(路径 $\mathrm{B}$ )得到亚胺离子 13 和自由基中间体 11. 最后, 13 的水解得到末端产物 $10 \mathrm{a}$, 同时生成副产物二 甲基胺氢溴酸盐.

2017 年, Kumar 等 ${ }^{[20]}$ 以 Langlois 试剂 $\left(\mathrm{CF}_{3} \mathrm{SO}_{2} \mathrm{Na}\right)$ 和 9,10-二酮菲蒽 (PQ)作为光氧化还原催化剂, 水作为氧 源, 实现了光诱导氧化、无金属串联自由基环化、三氟 甲基化和 1,6-烯炔的脱氢氧化反应(Eq. 3). 该方案可以 得到各种含 $\mathrm{CF}_{3}$ 的 $\mathrm{C}(3)$-芳酰基/酰化的苯并呋喃, 苯并 噻吩和吲哚.

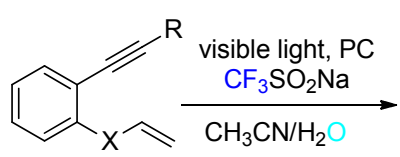

$14 \mathrm{X}=\mathrm{O}, \mathrm{S}, \mathrm{N}$

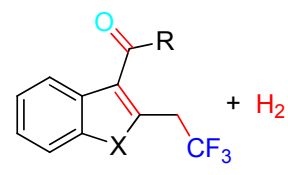

15

43 examples up to $76 \%$ yield Synthesis of two $\mathrm{CF}_{3}$-drugs
其机理研究表明(Scheme 4), 在光诱导产生的 PQ 激发态作用下, $\mathrm{CF}_{3} \mathrm{SO}_{2} \mathrm{Na}$ 产生 $\mathrm{CF}_{3}$ 自由基, 将 $\mathrm{CF}_{3}$ 自由 基加到烯烃上, 经环化得到乙烯基自由基, 然后经电子 转移生成乙烯基阳离子, 或者电子转移可以从加入 $\mathrm{CF}_{3}$ 的烯烃部分发生, 形成碳阳离子, 再经历阳离子环化产 生乙烯基碳阳离子, 随后向乙烯基阳离子中加入水, 除 去氢气，形成三氟甲基化的 C(3)-芳酰基/酰化的杂环化 合物. 该方法能够使不稳定的 1,6-烯炔底物氧化, 同时 在无氧化剂的条件下产生氢气, 且避免了过氧化产物的 产生.

2018 年, 魏伟等 ${ }^{[21]}$ 在可见光诱导条件下, 由异氰化
物、硫醇和水合成硫代氨基甲酸酯(Eq. 4). 通过简单地 使用廉价的玫瑰红作为光催化剂, 水作为反应试剂以及 环境友好的助溶剂, 以良好的产率得到各种硫代氨基甲 酸酯. 机理研究发现反应是通过单电子转移过程形成自 由基得到反应产物.

2019 年, 谢劲等 ${ }^{[22]}$ 使用廉价的 $\mathrm{D}_{2} \mathrm{O}$ 作为理想的気 源，在可见光与膦自由基协同作用下最终以 $86 \%$ 的收率 得到 96\%氞代的产物(Eq. 5). 该反应对各种吸电子和给 电子的邻、间及对位取代的芳香羧酸都具有很好的兼容 性, 并以较优的产率得到高気代化产物. 反应底物含有 的氨基、羟基、卤素、醛基、羰基、硽酸酯、末端烯烃 及末端炔烃等敏感的官能团均不影响反应的正常进行. 喹啉和吲哚等杂芳族酸以及脂肪羧酸也可以顺利进行 脱氧氝化. 在相同的条件下, 只需用 $\mathrm{H}_{2} \mathrm{O}$ 代替 $\mathrm{D}_{2} \mathrm{O}$, 可 以在温和条件下选择性还原羧酸成醛, 并且具有良好的 选择性和官能团兼容性.

\section{3 水作为反应介质参与可见光反应}

传统的有机合成在很大程度上依赖于有机溶剂, 包 括溶解组分和促进化学反应, 因为许多试剂和活性物质 与水不相溶或不混溶. 与反应物相比, 有机溶剂大量被 使用，所以溶剂问题一直是环境问题的焦点. 自 1882

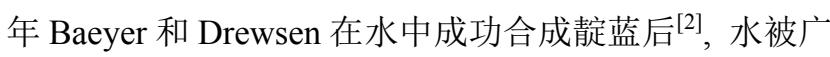
泛用作有机合成反应研究的溶剂, 包括亲核取代反 应 $^{[23]}$ 、氧化还原反应、Claisen 重排反应 ${ }^{[7]}$ 和 Diels-Alder 反应 ${ }^{[24]}$ 等. 近年来, 以水为溶剂的金属催化、生物催化、 


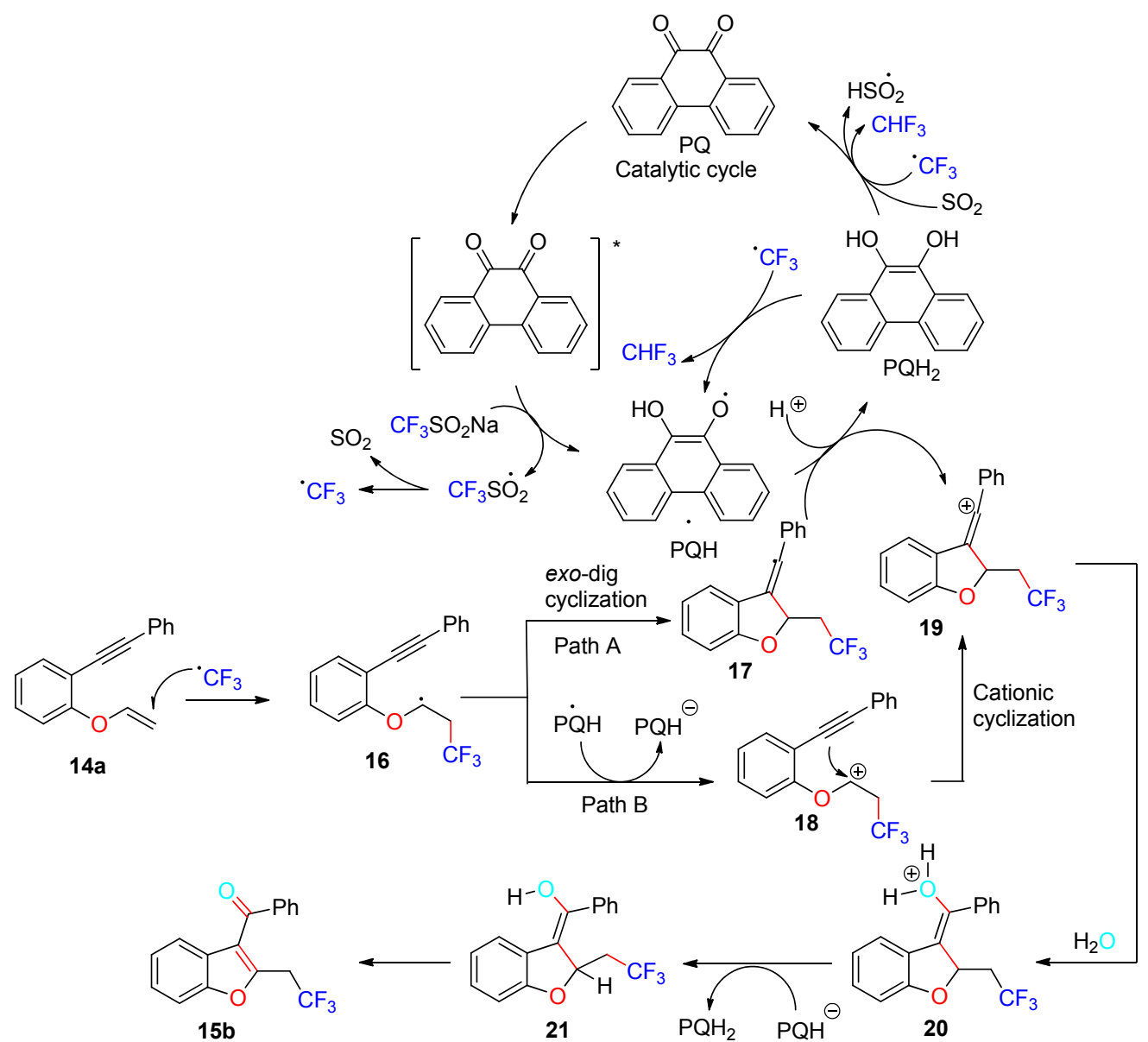

图式 4 在水中可见光诱导氧化剂和无金属脱氢级联三氟甲基化和 1,6-烯炔的氧化的机理

Scheme 4 Mechanism of visible light-induced oxidant and metal-free dehydrogenation cascade trifluoromethylation and oxidation of 1,6-enyne in water

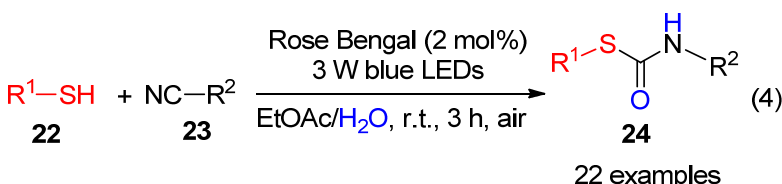

$$
\begin{aligned}
& \text { up to } 88 \% \text { yield }
\end{aligned}
$$

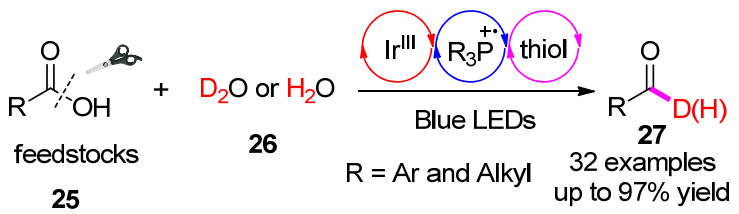

胶束催化等在加快反应速率中具有诱人的应用前景. 与 传统溶剂相比, 水是生态系统中最普遍和最友好的溶 剂, 具有独特的优势. 首先, 水具有安全、廉价、无毒和 无污染等特点 ${ }^{[18]}$, 契合现代绿色化学的理念; 其次, 由 于水自身能电离出 $\mathrm{H}^{+}$与 $\mathrm{OH}^{-}$, 对一些有机溶剂具有酸 碱催化作用; 最后, 由于大量有机物在水中的溶解度较 小, 当反应本身冷却到室温时, 反应产物可析出或分层,
后处理过程极为简便.

\section{1 水与有机溶剂作为混合溶剂的可见光催化反应}

由于大多数底物不能完全溶解在水中, 然而溶解度 一般是反应发生的先决条件, 溶解度低将大大影响反应 的进程和结果，因此在许多 “水相反应” 的例子中，通 常使用水混合有机溶剂以便提高有机反应物在水中的 溶解度 ${ }^{[25]}$.

2018 年, 龚行等 ${ }^{[26]}$ 在水一乙腈混合物中, 用 $\mathrm{Ce}^{4+}$ 介 导串联氧化开环/环化反应合成了 1-四氢菜酮(Eq. 6). 该 反应在 $0{ }^{\circ} \mathrm{C}$ 下开放式反应器中反应，在 $30 \mathrm{~s}$ 内快速完 成, 且适用于各种环丁醇衍生物.

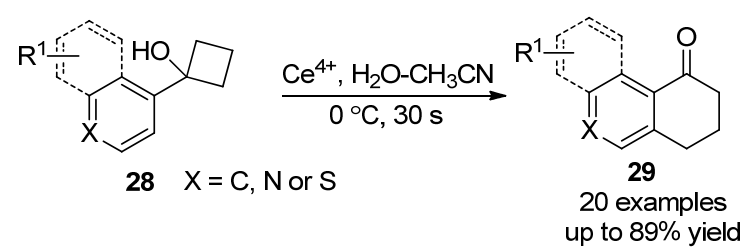

该反应的反应机理如 Scheme 5, 通过 CAN 介导的 
单电子转移(SET)过程形成氧自由基中间体 30. 然后以 环张力释放为驱动力, 发生 $\mathrm{C}-\mathrm{C}$ 均裂生成碳自由基 $\mathbf{3 1}$. 随后，进行自由基加成反应，形成离域自由基中间体 32. 最后发生由 $\mathrm{Ce}\left(\mathrm{NH}_{4}\right)_{2}\left(\mathrm{NO}_{3}\right)_{6}(\mathrm{CAN})$ 介导的另一个 SET 过程, 从而实现芳构化产物.

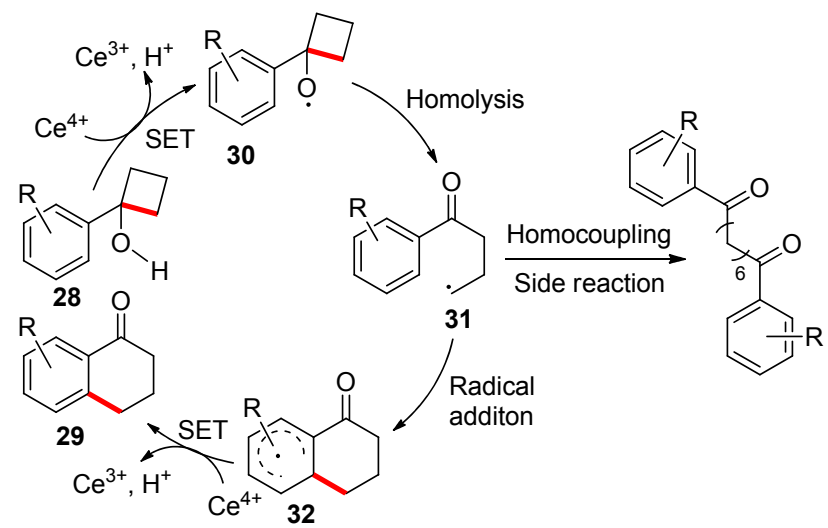

图式 5 水-乙腈中二次串联氧化开环/环化反应合成 1-四氢萗 酮的机理

Scheme 5 Mechanism of synthesis of 1-tetralone by double-stage oxidative ring-opening/cyclization reaction in wateracetonitrile

2017 年, 吴银素等 ${ }^{[27]}$ 报道了一种靛红、丙二腈和可 烯醇化的 $\mathrm{C}-\mathrm{H}$ 活化化合物(2-羟基菜 1,4-二酮、4-羞基 香豆素和双甲酮)的一锅三组分反应(Eq. 7), 提供了一 种可见光照射, 室温下在水-乳酸乙酯中, 合成螺噁吲 哚-吡喃衍生物的高效环保的方案.

其可能的自由基反应机理如 Scheme 6. 首先, 在共 溶剂 $\left(\mathrm{EL} / \mathrm{H}_{2} \mathrm{O}\right)$ 中用可见光照射, 通过丙二腈的互变异构 形成中间体 37, 37 和靛红在溶液中经历 Knoevenagel 缩 合, 得到氰基烯烃中间体 38, 同时除去水. 然后可见光 活化 38 形成自由基中间体 39, 39 从丙二腈中夺取亚

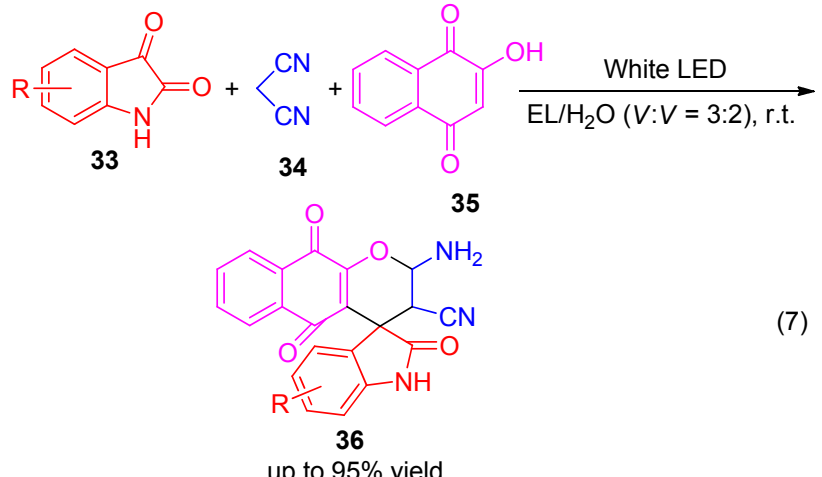

甲基氢, 产生丙二腈基自由基, 其反过来从 2-羟基萗1,4-二酮中提取氢得到中间体 41. 随后 41 进一步与 40 反应得到 42 , 最后进行分子内环化, 得到所需产物. 该 方法显示出显著的优点, 例如产率高, 反应条件温和清 洁. 清洁可见光作为能源, 不使用催化剂, 使用乳酸乙 酯/水作为环境友好的溶剂, 且在室温下进行多组分反 应，无色谱分离，适用于大规模合成.

2019 年, 魏伟等 ${ }^{[28]}$ 开发了一种以空气中的 $\mathrm{O}_{2}$ 作为 氧化剂, 在可见光驱动下, 使芳基二偶氮砜与硫醇氧化 偶联，构建不对称亚砜的反应(Eq. 8). 该反应使用乙腈 和水作混合溶剂, 可在室温下, 无需催化剂和添加剂的 条件下进行，由简单且容易获得的原料以良好的产率获 得结构多样的亚砜结构. 具有操作简单、选择性高、环 境友好和无需催化剂等优点, 在有机合成中极具吸引 力.

\section{2 纯水相可见光催化反应}

除了使用混合溶剂以提高反应物在水中的溶解度 以外，引入极性官能团提高反应物的亲水性，也能够提 高化合物的水溶性 ${ }^{[6 a]}$. 人们还尝试通过添加外加
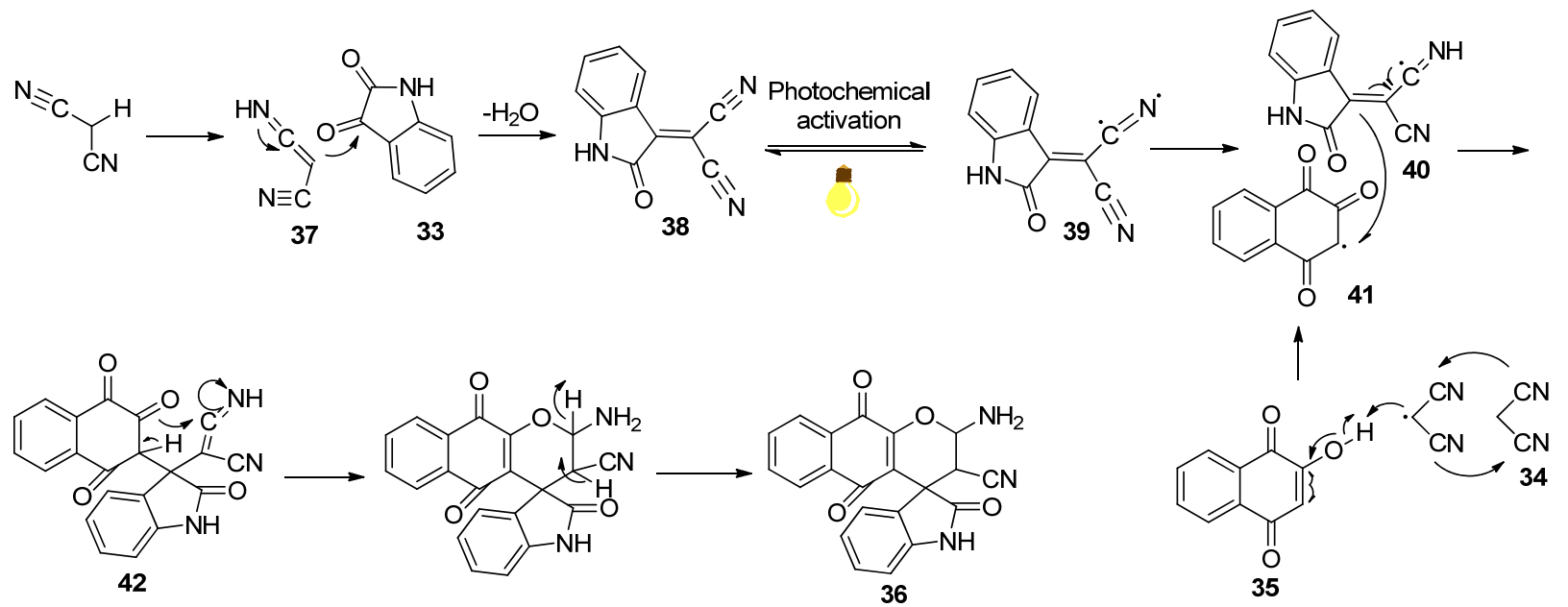

图式 6 在乳酸乙酯水溶液中无催化剂可见光促进一锅法合成螺内吲哚-吡喃衍生物

Scheme 6 Catalyst-free, visible-light promoted one-pot synthesis of spirooxindole-pyran derivatives in aqueous ethyl lactate 


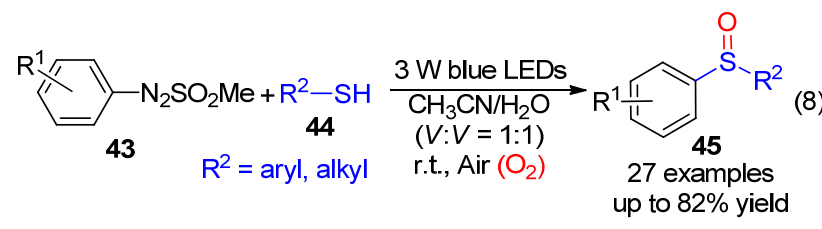

配体 ${ }^{[29]}$ 、表面活性剂 ${ }^{[30]}$ 或采用超声波 ${ }^{[31]}$ 等手段以解决有 机底物在水相中溶解度低的问题, 从而实现纯水相中的 有机反应.

2014 年, 薛东等 ${ }^{[32]}$ 报道了一种可见光促进的, $N$-杂 芳烃与芳基重氮盐在水中的 “基团型” 偶联反应, 在室 温下用 $\left[\mathrm{Ru}(\mathrm{bpy})_{3}\right] \mathrm{Cl}_{2} \cdot 6 \mathrm{H}_{2} \mathrm{O}$ 作为光敏剂, 家用灯泡作为 光源进行反应(Eq. 9). 该反应适用于各种取代的吡啶以 及一系列的氧杂葱、噻唑、吡嗪和哒嗪, 并且仅形成具 有不同区域选择性的单取代产物.

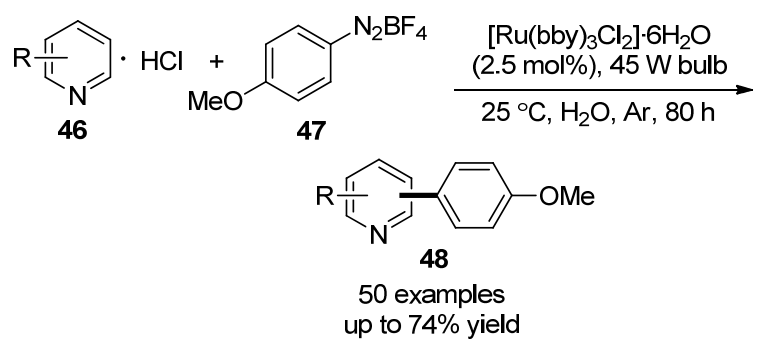

该偶联反应的反应机理见 Scheme 7, 其中有三个关 键步骤: (1)光照射催化剂 49 , 产生激发的 $\left[\mathrm{Ru}(b p y)_{3}\right]^{\mathrm{I}^{\mathrm{I}}}{ }^{*}$ 50; (2) 通过单电子转移, 电子从 $\mathbf{5 0}$ 转移到芳基重氮盐, 释放出苯基, 同时催化剂被氧化成 $\left[\mathrm{Ru}(\mathrm{bpy})_{3}\right]^{\mathrm{III}}(\mathbf{5 1})$; (3) 苯基加成到吡啶盐酸盐上, 得到新的自由基中间体, 随 后通过两种可能的途径将其转化为碳阳离子中间体: 通 过强氧化 $\left[\mathrm{Ru}(\mathrm{bpy})_{3}\right]^{\mathrm{III}}$ (光催化芳基化, 途径 a)或由芳基 重氮盐氧化(途径 b). 考虑到两种氧化剂的还原电位以 及避光芳基化的观察, 途径 $\mathrm{b}$ 不太可能发生自由基链转 移反应. 最后, 碳阳离子中间体的去质子化使芳族体系 再生, 得到所需的偶联加合产物.

2018 年, 夏成才等 ${ }^{[33]}$ 报道了一种在温和条件下，通 过可见光介导, 镍(II)催化, 芳基胺和吡唑之间的 $\mathrm{C}-\mathrm{N}$ 交叉偶联, 区域选择性合成含吡唑化合物的绿色方法 (Eq. 10). 该反应底物适用范围广，适用于含甲基、苯基、 卤素、苯并三唑的芳基胺或其它荎酰胺的化合物的合成, 但带吸电子基团( $\mathrm{CN}$ 和 $\mathrm{NO}_{2}$ ) 的吡唑衍生物不能进行该 $\mathrm{C}-\mathrm{N}$ 交叉偶联反应.

该反应单电子转移机制见 Scheme 8. 首先通过可见 光照射, 激发光催化剂 $(\mathrm{PC})$ 形成的激发物质 $\mathrm{PC}^{*}$ 与吡唑 (53)发生单电子转移(SET), 产生吡坐自由基 $\mathbf{5 5}$ 和 $\mathrm{PC}^{\circ-}$. 随后, $\mathrm{PC}^{\cdot-}$ 被 $\mathrm{H}_{2} \mathrm{O}_{2}$ 氧化产生羟基自由基和 $\mathrm{PC}$. 同时,

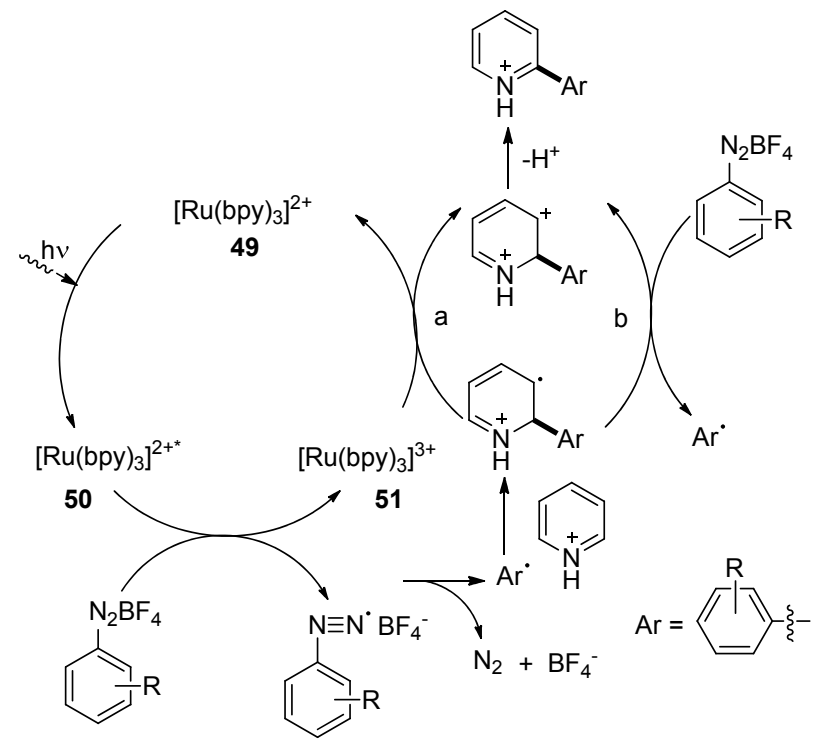

图式 7 在水中光催化 $N$-杂芳烃与芳基重氮盐的直接芳基化 反应的机理

Scheme 7 Mechanism of photocatalytic direct arylation of $\mathrm{N}$-heteroarene with aryl diazonium salt in water

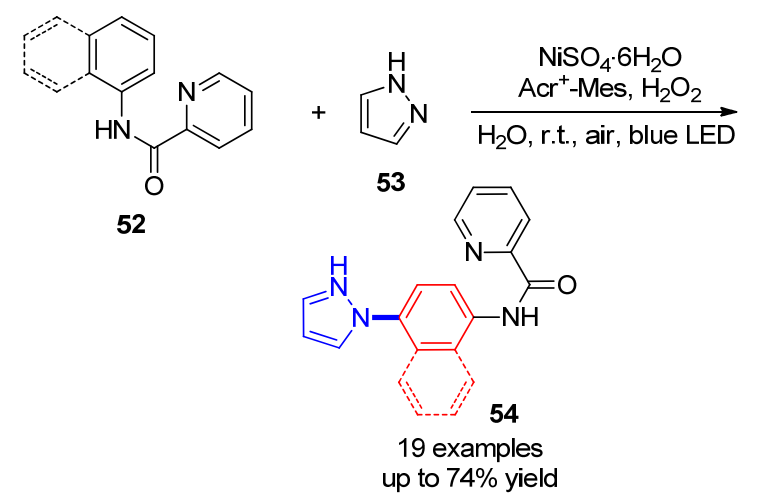

$\mathrm{Ni}^{\mathrm{II}} \mathrm{L}_{n}$ 与底物 52 结合, 氧化羟基自由基, 生成芳基$\mathrm{Ni}^{\mathrm{III}} \mathrm{L}_{n}$ 络合物 56 和 $\mathrm{H}_{2} \mathrm{O}$. 然后通过 SET 过程形成芳基$\mathrm{Ni}^{\mathrm{II}} \mathrm{L}_{n}$ 络合物 $\mathbf{5 7}$. 吡唑基 55 进攻芳基 $-\mathrm{Ni}^{\mathrm{II}} \mathrm{L}_{n}$ 络合物 $\mathbf{5 6}$ 生成芳基 $-\mathrm{Ni}^{\mathrm{iI}} \mathrm{L}_{n}$ 络合物 $\mathbf{5 8}, \mathbf{5 8}$ 经去质子化形成芳基$\mathrm{Ni}^{\mathrm{II}} \mathrm{L}_{n}$ 络合物 59 后，通过金属离解过程获得目标产物 54. 该策略为含有吡唑的生物活性分子的绿色合成提供 了强有力的方法.

目前已经开发了可回收的非均相催化剂代替单一 金属催化剂，在许多反应中表现出良好的催化活性. 然 而，这些非均相催化剂仍然存在缺陷，比如合成总是需 要多个步骤, 结构确认难度大. 因此, 在水中用简单且 环保的催化剂进行反应仍然是比较好的选择.

2013 年, 王心晨等 ${ }^{[34]}$ 报道了一种绿色、无金属的光 催化过程(Eq. 11). 在介孔石墨氮化碳(mpg-CN)光催化 剂介导下，于水相中使用分子氧、水和可见光与 4-甲 


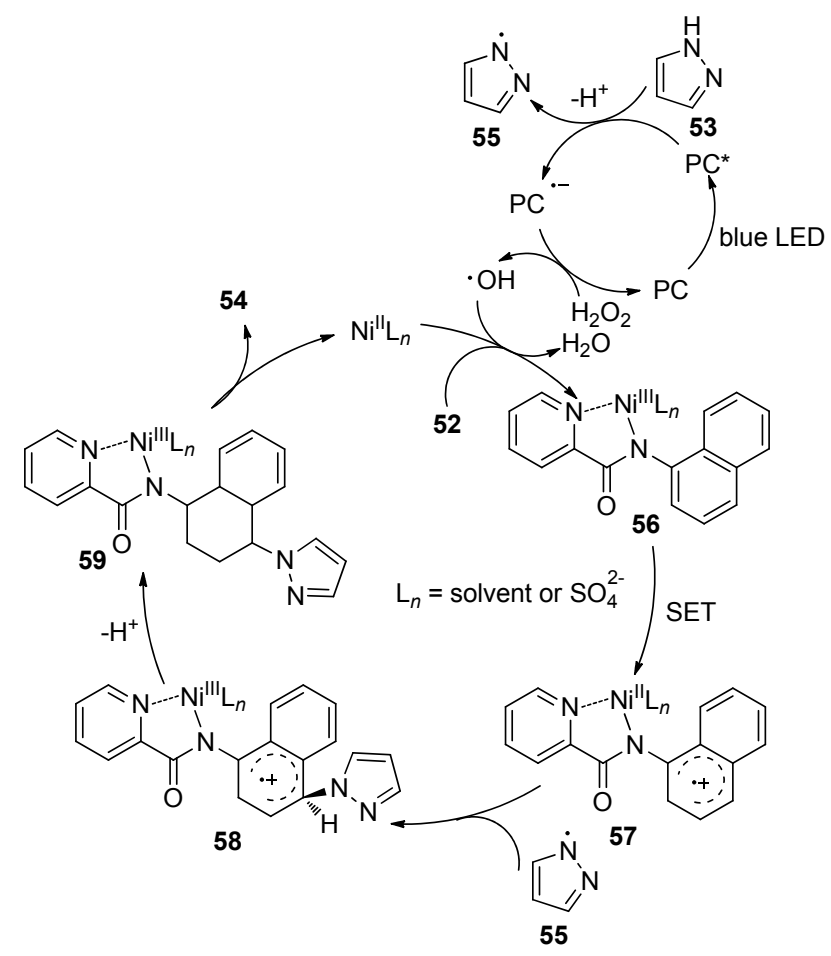

图式 8 可见光介导镍(II)催化的水中 $\mathrm{C}-\mathrm{N}$ 交叉偶联反应的 机理

Scheme 8 Mechanism of visible light mediated nickel(II) catalyzed $\mathrm{C}-\mathrm{N}$ cross-coupling reaction in water

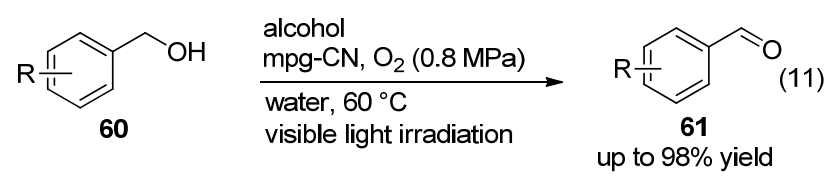

氧基茮醇(MBA)发生选择性氧化反应. 高稳定性的 $\mathrm{CN}$ 半导体可以通过改变不同的参数来调节光系统的催化 性能，例如和强酸/超强酸的协同催化. 在该反应中,
水相中 4-甲氧基苄醇可以在中性条件下，60 ${ }^{\circ} \mathrm{C}$ 以 $89 \%$ 的高选择性转化成相应的醛. 水相中 4-甲氧基芐醇可 以在中性条件下, $60{ }^{\circ} \mathrm{C}$ 以 $89 \%$ 的高选择性转化成相应 的醛，转化率为 $56 \%$. 当 $\mathrm{HCl}$ 存在时，该体系催化苄醇 转化为茮醛(49\%), 具有 $93 \%$ 的高选择性, 并且催化剂 可回收, 而在强酸性溶液中不会失活.

2018 年, 蔡春课题组 ${ }^{[8]}$ 报道了一种将光氧化还原催 化与胶束催化相结合的胶束光催化体系, 用于催化原位 亚硝化芳胺的芳基化反应(Eq. 12). 该方法使用了 Triton X-100 作为外加表面活性剂, 有机染料曙红 B 作为光催 化剂, 开发了不含过渡金属的水相光催化体系. 该系统 在室温下可以在没有任何有机溶剂和添加剂的情况下, 实现光催化芳基化反应. 该反应具有广泛的底物适用范 围，适用于各种官能团取代的亚硝化芳胺化合物，包括 烷基、烷氧基、硝基、氰基、烷氧基和三氟甲基等，在 反应过程中, 通常带有吸电子和中性取代基的苯胺比带 有给电子基团的苯胺获得更高的收率，空间效应对这种 转化没有显着影响。该方案操作简单，催化系统中 Triton X-100 和曙红 B 都是市售且价格便宜; 水作为唯 一的反应介质，可见光作为能源，两者都安全、清洁、 丰富和廉价; 含有表面活性剂的含水反应介质可以循环 数次, 具有清洁节能的优点.

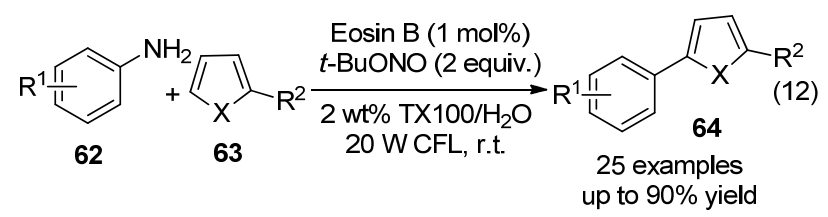

2018 年, Lipshutz 等 ${ }^{[35]}$ 报道了一种新的催化体系 (Scheme 9), 使用两性 PQS 附着的光催化剂, 在水中聚 集成纳米胶束. 这种共价结合的物质能够在不存在添加

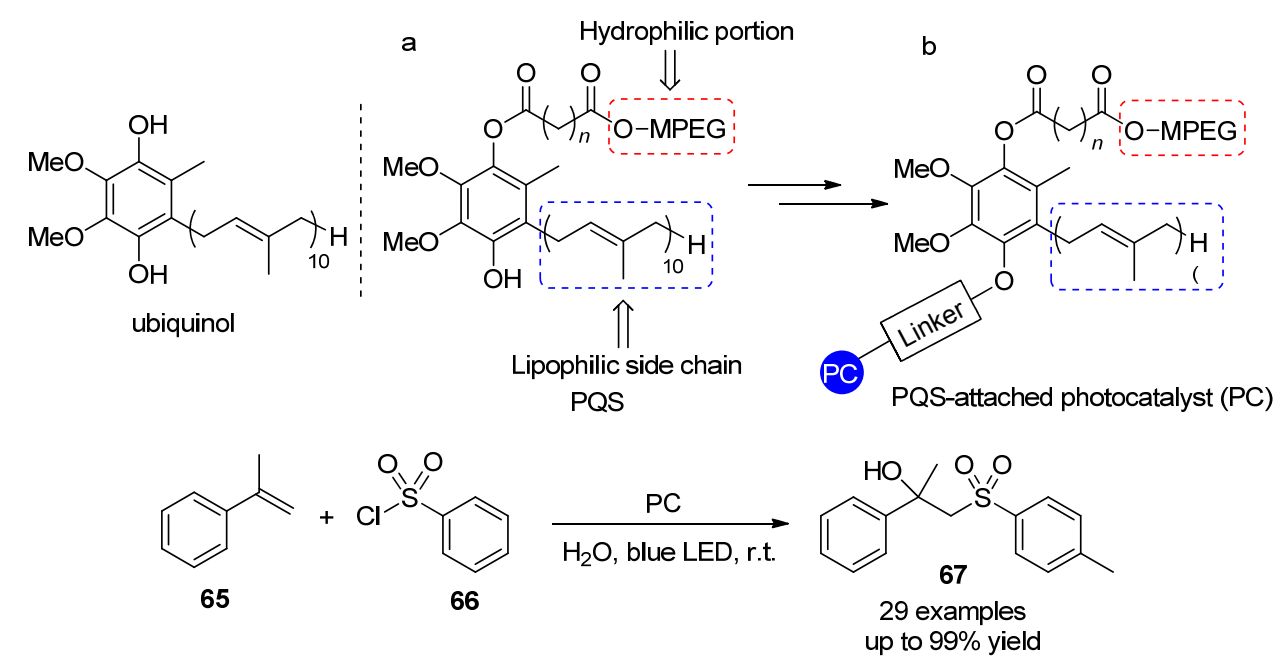

图式 9 两亲的 PQS 连接的铱光敏剂催化的光致还原反应

Scheme 9 Photoreduction reaction catalyzed by amphiphilic PQS-linked iridium 
剂或共溶剂的情况下进行基于 Ir 的光催化氧化物催化. 使用这种新的催化策略的反应, 实现了室温下在水中进 行的光致还原催化, 无需加热或冷却, 整个含水反应混 合物容易进行烧瓶内循环. 在这种化学反应中, 水充当 “绿色” 反应介质, 可见光被用作安全和可再生的化学潜 力来源. 此外, 水介质和贵金属催化剂可以循环数次而 无需从反应容器中除去, 这提供了一种可持续催化的策 略.

地球上大部分植物和细菌通过光合作用完成对太 阳能的吸收、捕获、转移和储存. 在这个过程中, 来自 阳光的能量被叶绿素分子捕获并转化为化学能. 为了开 发清洁和可持续的能源, 越来越多的科研团队研究如何 模拟光合作用.

2019 年, 张明明及其团队 ${ }^{[36]}$ 以具有高荧光量子效 率的金属铂配合物分子笼为供体，以曙红 $\mathrm{Y}$ 为受体，通 过两种苂光分子的自组装在水溶液中制备了一种高效 的光捕获系统, 其能量转移效率为 $45 \%$. 该光捕获系统 被进一步作为光催化剂, 在可见光照射下, 铂分子笼作 为天线传递光源来激发曙红 $\mathrm{Y}$ 产生可以催化反应的自 由基, 使其表现出比单独的曙红 $\mathrm{Y}$ 更好的光催化活性. 该系统组装形成的超分子胶束还可以减轻曙红 Y 的光 漂白效应, 使其可以长时间保持较高的催化活性. 该研 究不仅提供了一种从金属铂配合物分子笼为供体的高 效光捕获体系, 而且还利用其输出能量来催化析氢交叉
偶联反应(Scheme 10)，实现了对叶绿体等光合作用载 体结构和功能的系统模拟, 推动人们对光合作用的进一 步研究.

2019 年，王否和李品华等 ${ }^{[37]}$ 道了一种使用 $N$-烯丙 基苯甲酰胺与 $\mathrm{CF}_{3} \mathrm{SO}_{2} \mathrm{Na}$ (Langlois 试剂)在可见光诱导 光催化剂存在下水介质中一步合成三氟甲基化二氢异 喹啉酮的策略(Eq. 13)。该反应以高产率合成相应的三 氟甲基化二氢异喹啉酮，在温和条件下具有良好的官能 团耐受性.

该反应的机理见 Scheme 11. 首先, $\left[\mathrm{Ru}(\mathrm{bpy})_{3}\right]^{2+}$ 在 可见光照射下被激活到其激发态 $\left[\mathrm{Ru}(\mathrm{bpy})_{3}\right]^{2+} *$. 接下来, $\mathrm{TBHP}$ 从激发的 $\left[\mathrm{Ru}(\mathrm{bpy})_{3}\right]^{2+} *$ 获得能量(能量转移过程), 通过过氧化物键的均裂解产生羟基和叔丁氧基. 然后叔 丁氧基或羟基与 $\mathrm{CF}_{3} \mathrm{SO}_{2} \mathrm{Na}$ 反应形成 $\mathrm{CF}_{3}$ 自由基(71). 随 后，获得的 $\mathrm{CF}_{3}$ 自由基(71)被加入到 $N$-烯丙基苯甲酰胺 的双键中，得到自由基中间体 72, 然后进行分子内环 化，得到自由基中间体 73. 73 被叔丁氧基或着基氧化， 通过 SET 过程产生阳离子中间体 74. 最后, 74 失去质子 产生所需产物, 同时形成水或叔丁醇.

\section{4 水在生物体内参与可见光反应}

可见光照射下的水相反应在有机合成中应用较多， 但是在生命体内的研究还非常的罕见. 若将其应用到活

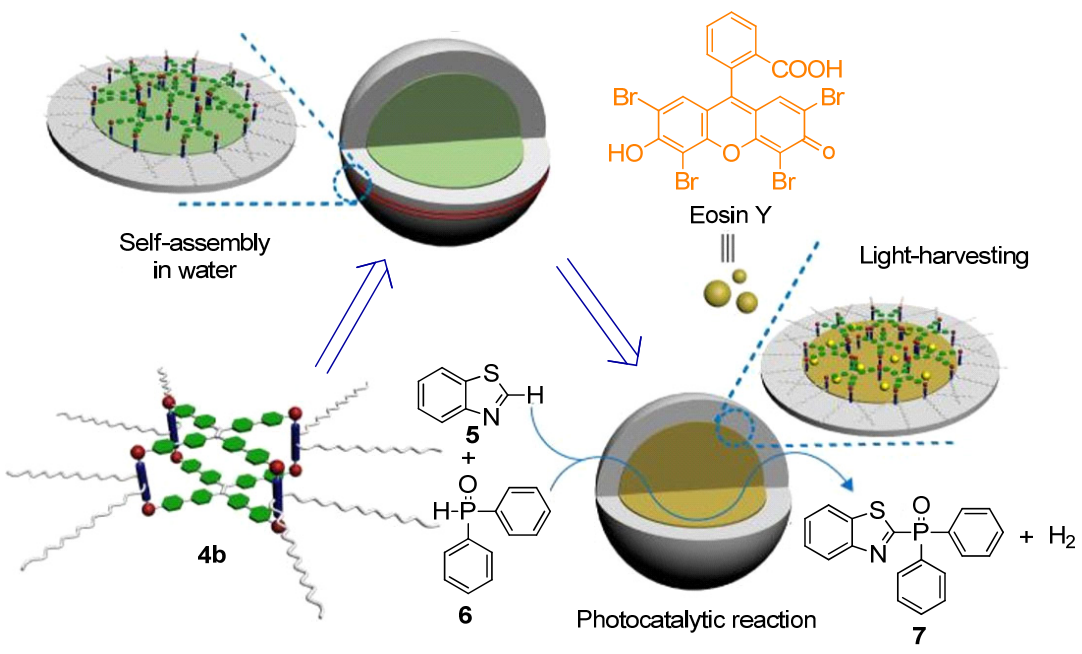

图式 10 基于水溶性荧光金属铂分子笼的光捕获系统用于光催化交叉偶联析氢反应

Scheme 10 Queous platinum(II) cage-based light-harvesting system for photocatalytic cross-coupling hydrogen evolution Reaction
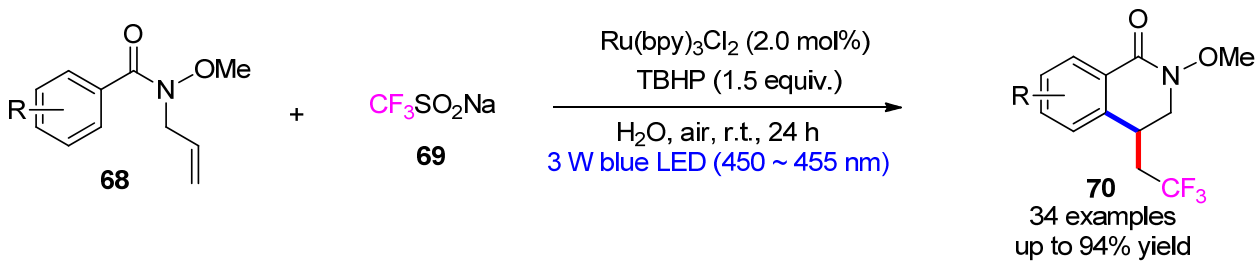


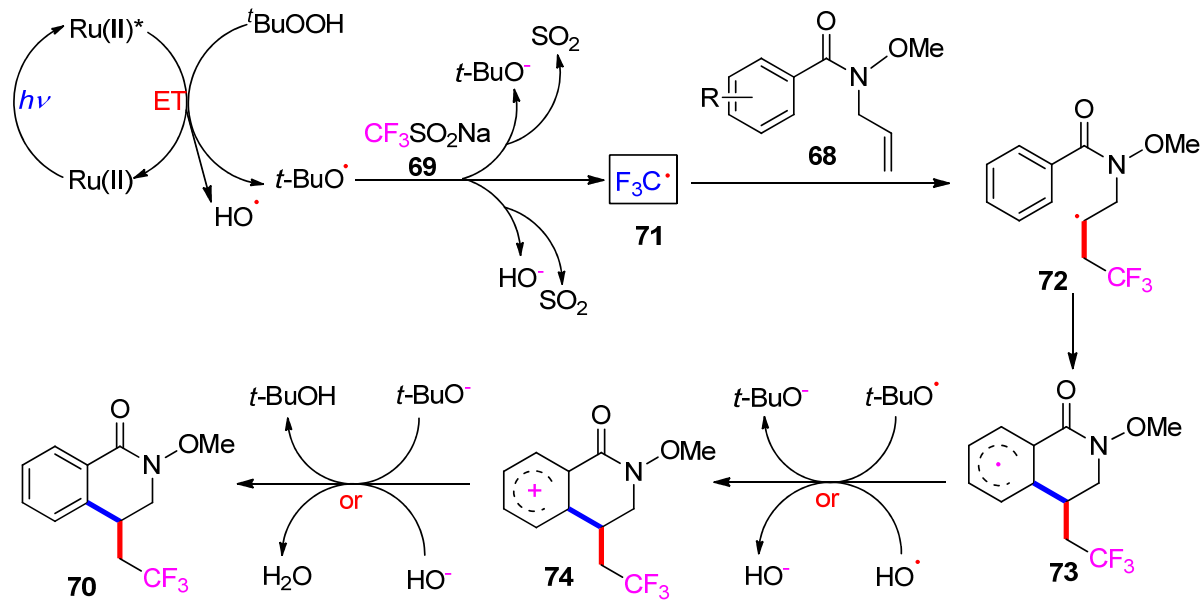

图式 11 室温下可见光催化 $N$-烯丙基苯甲酰胺与 $\mathrm{CF}_{3} \mathrm{SO}_{2} \mathrm{Na}$ 在水相中合成三氟甲基化二氢异喹啉酮

Scheme 11 Visible-light-induced radical cyclization of $\mathrm{N}$-allylbenzamide with $\mathrm{CF}_{3} \mathrm{SO}_{2} \mathrm{Na}$ to trifluoromethylated dihydroisoquinolinones in water at room temperature

细胞中的细胞质中, 实时调控细胞生命活动, 对研究细 胞的生理功能具有重要价值.

2019 年, 陈以旳等 ${ }^{[38]}$ 报道了将常用于苂光成像的 有机苂光分子作为生物相容的光催化剂, 在细胞内利用 氧气及抗氧化剂通过光催化氧化还原反应产生过氧化 氢, 从而进行脱硼羟基化反应去笼, 释放生物活性分子. 使用家用 CFL 灯或低能量蓝色 LED 灯作为光源, 该反 应在中性水溶液中可以对含有酚、羟基、氨基基团的生 物分子实现高效的光去笼释放 (Scheme 12). 该方法可 以通过光释放异丙基- $\beta-d-d$-硫代半乳糖苷(IPTG)分子有 效光调控大肠杆菌中的蛋白表达, 并且可以通过光释放 巴氯芬药物有效调控 $\gamma$-氨酪酸 $(\mathrm{GABAB})$ 受体功能, 从 而对小鼠脑片中神经细胞的膜电位进行高时空分辨率 的光调控. 最后使用线粒体定位苂光染料作为具有定位 效应的光催化剂, 借助于过氧化氢在细胞内的有限自由 扩散, 实现了亚细胞定位的可见光去笼. 该研究展示了 光催化氧化还原反应应用于细胞及生命体系研究的广 阔前景.

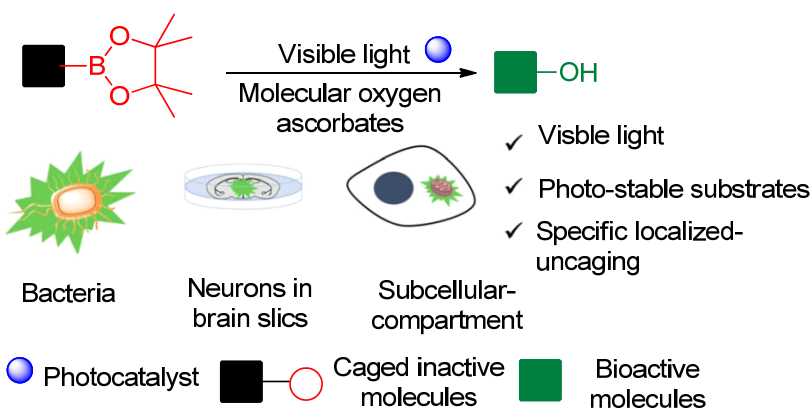

图式 12 活细胞内通过光催化反应实现可见光释放生物活性 分子

Scheme 12 Visible light release bioactive molecules in living cells by photocatalytic reaction

\section{5 总结与展望}

可见光和水都是丰富的自然资源, 在生命中起着重 要作用, 水是生化反应的介质, 光是生化反应的能源, 因此, 研究温和条件下水相中的光照反应具有重要的意 义. 水参与的可见光催化反应近年来获得了显著的进 展, 但是在纯水相中进行的可见光催化反应研究相对较 少, 反应类型种类还不够多, 在纯水相中反应的规律还 没有充分揭示. 随着近年来人们对纯水相中的光催化反 应的日益关注, 探索新型的有机反应, 发展新型光催化 剂成为化学家的研究热点. 随着适用于水相反应的新的 光催化剂(如新型的表面活性剂型光敏剂)的出现, 为发 展纯水相光催化反应提供了新的策略. 开发出新型基于 水相反应的光敏剂, 将光敏剂设计成表面活性剂型催化 剂, 将胶束效应、疏水活化和可见光催化有机结合起协 同活化惰性底物，从而在温和条件下实现传统光敏剂在 水相很难实现的催化反应. 这个挑战性的课题对促进绿 色化学的发展具有重要的意义, 同样对于揭示生命体内 的生化反应规律也具有重要的意义. 因此, 纯水相中的 可见光催化反应还有广阔的发展空间.

\section{References}

[1] Anastas, P.; Eghbali, N. Chem. Soc. Rev. 2010, 39, 301.

[2] Nicewicz, D. A.; MacMillan, D. W. C. Science 2008, 322, 77.

[3] Stillinger, F. H. Nature (London) 1999, 401, 850.

[4] (a) Simon, M.-O.; Li, C.-J. Chem. Soc. Rev. 2012, 41, 1415.

(b) Zhou, Z.; Duan; J.; Mu, X.; Xiao, S. Chin. J. Org. Chem. 2018, 38,585 (in Chinese). (周坥, 段建凤, 穆小静, 肖尚友, 有机化学, 2018, 38, 585.)

[5] Anastas, P. T. Chem. Rev. 2007, 107, 2167.

[6] (a) Itami, K.; Yoshida, J.-I. Chem. Rec. 2002, 2, 213.

(b) Li, C.-J.; Meng, Y.; Yi, X.-H.; Ma, J.; Chan, T.-H. J. Org. Chem. 1997, 62, 8632.

[7] Nicolaou, K. C.; Xu, H.; Wartmann, M. Angew. Chem., Int. Ed. 2005, 44, 756 . 
[8] Bu, M.-J.; Lu, G.-P.; Jiang, J.; Cai, C. Catal. Sci. Technol. 2018, 8, 3728 .

[9] Huang, Y.; Wei, W. Prog. Chem. 2018, 30, 1819 (in Chinese). (黄依铃, 魏文廷, 化学进展, 2018, 30, 1819.)

[10] Fujishima, A.; Honda, K. Nature (London) 1972, 238, 37.

[11] (a) Fan, X.-Z.; Rong, J.-W.; Wu, H.-L.; Zhou, Q.; Deng, H.-P.; Tan, J. D.; Xue, C.-W.; Wu, L.-Z.; Tao, H.-R.; Wu, J. Angew. Chem., Int. Ed. 2018, 57, 8514 .

(b) Jiang, X.; Zhang, M.-M.; Xiong, W.; Lu, L.-Q.; Xiao, W.-J. Angew. Chem., Int. Ed. 2019, 58, 2402.

(c) Ye, S.; Li, X.; Xie, W.; Wu, J. Eur. J. Org. Chem. 2019 (DOI: 10.1002/ejoc.201900396).

(d) Cai, B.-G.; Xuan, J.; Xiao, W.-J. Sci. Bull. 2019, 64, 337.

(e) Chen, Y.; Lu, L.-Q.; Yu, D.-G.; Zhu, C.-J.; Xiao, W.-J. Sci. China, Chem. 2018, 62, 24.

(f) Chen, J.-R.; Yan, D.-M.; Wei, Q.; Xiao, W.-J. ChemPhotoChem 2017, $1,148$.

(g) Ren, L.; Ran, M.; He, J.; Qian, Y.; Yao, Q. Chin. J. Org. Chem. 2019, 39, 1583 (in Chinese).

(任林静, 苒茂刚, 何佳芯, 钱燕, 姚秋丽, 有机化学, 2019, 39, 1583.)

(h) Shang, T.-Y.; Lu, L.-H.; Cao, Z.; Liu, Y.; He, W.-M.; Yu, B. Chem. Commun. 2019, 55, 5408

(i) Wang, L.; Bao, P.; Liu, W.; Liu, S.; Hu, C.; Yue, H.; Yang, D.; Wei, W. Chin. J. Org. Chem. 2018, 38, 3189 (in Chinese). (王雷雷, 鲍鹏丽, 刘维维, 刘思䑣, 胡昌松, 岳会兰, 杨道山, 魏伟, 有机化学, 2018, 38, 3189.)

[12] Zhang, W.-M.; Dai, J.-J.; Xu, J.; Xu, H.-J. J. Org. Chem. 2017, 82, 2059.

[13] (a) Chen, J.-R.; Hu, X.-Q.; Lu, L.-Q.; Xiao, W.-J. Chem. Soc. Rev. 2016, 45, 2044.

(b) Hopkinson, M. N.; Sahoo, B.; Li, J.-L.; Glorius, F. Chem.-Eur. J. 2014, 20, 3874 .

(c) Prier, C. K.; Rankic, D. A.; MacMillan, D. W. C. Chem. Rev. 2013, 113, 5322 .

(d) Qiu, G.; Li, Y.; Wu, J. Org. Chem. Front. 2016, 3, 1011.

(e) Reckenthaeler, M.; Griesbeck, A. G. Adv. Synth. Catal. 2013, 355, 2727.

(f) Xuan, J.; Xiao, W.-J. Angew. Chem., Int. Ed. 2012, 51, 6828

[14] Li, L.; Huang, M.; Liu, C.; Xiao, J. C.; Chen, Q. Y.; Guo, Y.; Zhao, Z. G. Org. Lett. 2015, 17, 4714.

[15] Zhang, M.; Ruzi, R.; Li, N.; Xie, J.; Zhu, C. Org. Chem. Front. 2018, 5,749 .

[16] Hou, H.; Zhu, S.; Pan, F.; Rueping, M. Org. Lett. 2014, 16, 2872.

[17] (a) Allavena, M. Mol. Eng. 1995, 5, 403.

(b) Head-Gordon, T.; Hura, G. Chem. Rev. 2002, 102, 2651.

[18] Jayaraman, M.; Batista, M. T.; Manhas, M. S.; Bose, A. K. Heterocycles 1998, 48, 1100

[19] Zou, Y.-Q.; Guo, W.; Liu, F.-L.; Lu, L.-Q.; Chen, J.-R..; Xiao, W.-J. Green Chem. 2014, 16, 3787.

[20] Jana, S.; Verma, A.; Kadu, R.; Kumar, S. Chem. Sci. 2017, 8, 6633.

[21] Wei, W.; Bao, P.; Yue, H.; Liu, S.; Wang, L.; Li, Y.; Yang, D. Org.
Lett. 2018, 20, 5291.

[22] Zhang, M.; Yuan, X. A.; Zhu, C.; Xie, J. Angew. Chem., Int. Ed. 2019, 58, 312.

[23] (a) Converso, A.; Burow, K.; Marzinzik, A.; Sharpless, K. B.; Finn, M. G. J. Org. Chem. 2001, 66, 4386.

(b) Converso, A.; Burow, K.; Marzinzik, A.; Sharpless, B.; Finn, M. G. J. Org. Chem. 2004, 69, 7336.

(c) Yudin, A. Aziridines and Epoxides in Organic Synthesis, Wiley-VCH Verlag GmbH \& Co. KGaA, 2006, p. 492.

[24] (a) Breslow, R.; Maitra, U.; Rideout, D. Tetrahedron Lett. 1983, 24, 1901.

(b) Grieco, P. A.; Garner, P.; He, Z.-M. Tetrahedron Lett. 1983, 24, 1897.

(c) Grieco, P. A.; Yoshida, K.; Garner, P. J. Org. Chem. 1983, 48 , 3137.

(d) Rideout, D. C.; Breslow, R. J. Am. Chem. Soc. 1980, 102, 7816.

[25] Lindstróm, U. M. Chem. Rev. 2002, 102, 2751.

[26] Fang, J.; Li, L.; Yang, C.; Chen, J.; Deng, G.-J.; Gong, H. Org. Lett. 2018, 20, 7308.

[27] Zhang, M.; Fu, Q.-Y.; Gao, G.; He, H.-Y.; Zhang, Y.; Wu, Y.-S.; Zhang, Z.-H. ACS Sustainable Chem. Eng. 2017, 5, 6175.

[28] Liu, Q.; Wang, L.; Yue, H.; Li, J.-S.; Luo, Z.; Wei, W. Green Chem. 2019, 21, 1609.

[29] (a) Cobo, I.; Matheu, M. I.; Castillór, S.; Boutureira, O.; Davis, B. G. Org. Lett. 2012, 14, 1728 .

(b) Ganesamoorthy, S.; Shanmugasundaram, K.; Karvembu, R. J. Mol. Catal. A: Chem. 2013, 371, 118 .

(c) Wallow, T. I.; Novak, B. M. J. Am. Chem. Soc. 1991, 113, 7411.

[30] (a) Lysen, M.; Koehler, K. Synthesis 2006, 692.

(b) Soomro, S. S.; Roehlich, C.; Koehler, K. Adv. Synth. Catal. 2011, 353, 767.

(c) Xie, L.-Y.; Jiang, L.-L.; Tan, J.-X.; Wang, Y.; Xu, X.-Q.; Zhang, B.; Cao, Z.; He, W.-M. ACS Sustainable Chem. Eng. 2019.

[31] (a) Solodenko, W.; Schoen, U.; Messinger, J.; Glinschert, A.; Kirschning, A. Synlett 2004, 1699.

(b) Zhang, J.; Yang, F.; Ren, G.; Mak, T. C. W.; Song, M.; Wu, Y Ultrason. Sonochem. 2007, 15, 115.

(c) Wu, C.; Lu, L.-H.; Peng, A.-Z.; Jia, G.-K.; Peng, C.; Cao, Z.; Tang, Z.; He, W.-M.; Xu, X. Green Chem. 2018, 20, 3683.

[32] Xue, D.; Jia, Z. H.; Zhao, C. J.; Zhang, Y. Y.; Wang, C.; Xiao, J. Chem.-Eur. J. 2014, 20, 2960.

[33] You, G.; Wang, K.; Wang, X.; Wang, G.; Sun, J.; Duan, G.; Xia, C. Org. Lett. 2018, 20, 4005.

[34] Long, B.; Ding, Z.; Wang, X. ChemSusChem 2013, 6, 2074.

[35] Bu, M.-J.; Cai, C.; Gallou, F.; Lipshutz, B. H. Green Chem. 2018 $20,1233$.

[36] Zhang, Z.; Zhao, Z.; Hou, Y.; Wang, H.; Li, X.; He, G.; Zhang, M. Angew. Chem., Int. Ed. 2019, 58, 8862.

[37] Zou, L.; Li, P.; Wang, B.; Wang, L. Green Chem. 2019, 21, 3362.

[38] Wang, H.; Li, W. G.; Zeng, K.; Wu, Y. J.; Zhang, Y.; Xu, T. L.; Chen, Y. Angew. Chem., Int. Ed. 2019, 58, 561 . 